\title{
Silver selective electrodes based on thioether functionalized calix[4] arenes as ionophores
}

\author{
Elżbieta Malinowska ${ }^{\text {a }}$, Zbigniew Brzózka ${ }^{a}$, Krzysztof Kasiura ${ }^{\text {a }}$, \\ Richard J.M. Egberink ${ }^{b}$, David N. Reinhoudt ${ }^{b, *}$ \\ a Department of Analytical Chemistry, Technical University of Warsaw, Noakowskiego 3, PL-00664 Warsaw, Poland \\ ${ }^{b}$ Department of Organic Chemistry, University of Twente, P.O. Box 217, 7500 AE Enschede, Netherlands
}

Received 10 February 1994; revised manuscript received 31 May 1994

\begin{abstract}
Silver selective electrodes based on thioether functionalized calix [ 4 ] arenes 1 and 2 as ionophores were investigated. For both ionophores the selectivity cnefficients $\left(\log k_{\mathrm{Ag}, \mathrm{M}}\right)$ were lower than -2.2 for $\mathrm{Hg}$ (II) and lower than -4.6 for other cations tested. The best results were obtained with membranes containing dithioether functionalized calix[4] arene (ionophore 2), potassium tetrakis (4-chlorophenyl)borate (KTpClPB) and bis(1-butylpentyl)adipate (BBPA) as a plasticizer. The $\mathrm{Ag}(\mathrm{I})$ response functions exhibited almost theoretical Nernstian slopes in the activity range $10^{-6}-10^{-1} \mathrm{M}$ of silver ions.
\end{abstract}

Keywords: Ion selective electrodes; Calix [4] arenes; Silver selective electrodes; Thioether functionalized calix [4] arenes

\section{Introduction}

The commercially available solid-state silver electrode based on $\mathrm{Ag}_{2} \mathrm{~S}$ is one of the oldest solid-state electrodes known in the literature [1-5]. This electrode exhibits an excellent selectivity towards alkali, alkaline earth, and most heavy metal ions. However, the strong mercury interference $\left(\log k_{\mathrm{Ag}, \mathrm{Hg}}>0\right)$ [6] is a weakness of this electrode. Due to the appropriate exchange mechanisms at the silver sulfide surface, a response to $\mathrm{Hg}^{2+}$ ions is always observed. Morf et al. [7] claimed on the basis of the defect theory for silver selective membranes that the response of silver halide or sulfide sensors to $\mathrm{Hg}^{2+}$ ions is neither Nernstian nor linear. Consequently the evaluation of the real $\mathrm{Ag}^{+} / \mathrm{Hg}^{2+}$ selectivity is a serious problem. This is the reason why a search for new silver selective sensors has been continued for the past few years. Improved mercury interference was obtained for a solid Araldite based silver selective electrode $\left(\log k_{\mathrm{Ag}, \mathrm{Hg}}=-4\right)$, although the interferences of other heavy metal ions (e.g., copper and cadmium; $\log k_{\mathrm{Ag}, \mathrm{M}}=-2.5$ ) were increased [8]. The ion-selective electrode based on chalcogenide glasses described by Vlasov [9] seems to be by far the best. Selectivity coefficients with $\log k_{\mathrm{Ag}, \mathrm{M}}<-5.5$ were obtained for alkali, alkaline earth and heavy metal ions. The interference of mercury was low (log $k_{\mathrm{Ag}, \mathrm{M}}=-3.2$ ). Pei et al. [10] presented a carbon paste electrode (carbon graphite with Nujol) as a potentiometric silver selective electrode. In this case the interferences of alkali and alkaline earth metal ions were negligible, for other cations the following values of $\log k_{\mathrm{Ag}, \mathrm{M} \text {. }}$ were obtained: zinc(II), cobalt(II) and

\footnotetext{
* Corresponding author.
} 
nickel(II), -3.2 ; lead(II), -2.3 ; copper, -2.1 ; and mercury (II) -0.7 .

Neutral carrier based silver selective electrodes are characterized by lower selectivities as compared with the above described solid-state electrodes [1-9]. In most cases crown ethers derivatives have been used as an ionophores [11-23]. It was found that enhanced selectivity for silver ions is achieved, compared with crown ethers, when one or more oxygen donor atoms are replaced by sulfur. Lai and Shih [15] used 1,4dithia-15-crown-5 (PVC/dibutyl phthalate) in an electrode for silver detection. This thiacrown ether showed the best sensitivity ( $40 \mathrm{mV} \mathrm{dec} .^{-1}$ ) of all crown ethers tested. The selectivity coefficients ( $\left.\log k_{\mathrm{Ag}, \mathrm{M}}\right)$ towards interfering alkali, alkaline earth and transition metal ions were higher than -3.5 (for sodium, potassium and magnesium). The strongest interferent was mercury $(+0.8)$. Better results were obtained by Oue et al. [16-18]. Both ion selective electrodes with monoand dithiacrown ethers in a PVC/dioctyl phthalate (DOP) matrix were highly silver selective. The selectivity coefficients for silver with respect to the heavy and transition metal ions are $<-3$ and with respect to alkali and alkaline earth metal ions $<-4$. The mercury ions interfered most scriously $\left(\log k_{\mathrm{Ag}, \mathrm{M}}=-2.2\right.$ to -1.5 ). The selectivities of the silver electrodes with different thiacrown ethers were quite similar in spite of different sulfur atoms in the thiacrown ethers. However, these parameters influence the sensitivity of the electrode (DOP plasticized membranes) especially at high silver activities. Oue et al. [18] observed also that the sensitivity of the electrode with $o$-nitrophenyl octyl ether ( $o$-NPOE) as a plasticizer was lower at high silver activities in comparison with the sensitivity of the electrode with bis(2-ethylhexyl) sebacate (DOS) or DOP. Casabo et al. [19-21] have described the performance of several thiabenzocrown ethers as ionophores for ion-selective electrodes (PVC/DOP). For all the ligands tested a Nernstian sensitivity towards silver was found. Mercury was the strongest interferent $\left(\log k_{\mathrm{Ag}, \mathrm{Hg}}-2\right.$ to -2.6$)$ while for other cations $\log$ $k_{\mathrm{Ag}, \mathrm{M}}<-4$. Also in this case it was found that despite the different geometry and number of sulfur donor atoms in the crown ethers, the selectivity coefficients of the corresponding electrodes were similar.

The possibility for a good coordination geometry for $\mathrm{Ag}^{+}$seems to be more important than the perfect ring size, explaining why lipophilic podand-likc ionophorcs display respectable chelating effects. Recently O'Connor et al. [22] have described calixarene derivatives with four sulfur and/or nitrogen donors atoms as ionophores for silver selective electrodes (PVC/oNPOE). All exhibited acceptable silver responses with the best (calix[4]arene substituted with four $-\mathrm{CH}_{2} \mathrm{CO}_{2} \mathrm{C}_{2} \mathrm{H}_{4} \mathrm{SCH}_{3}$ groups) giving a response of 50 $\mathrm{mV} \mathrm{dec} .^{-1}$ in the $\mathrm{Ag}(\mathrm{I})$ ion activity range of $10^{-4}$ to $10^{-1} \mathrm{M}$. Selectivity coefficients $\left(\log k_{\mathrm{Ag}, \mathrm{M}}\right)$ were higher than -3.3 for copper(II), nickel(II), cobalt(II), cadmium(II) and higher than -2.0 for potassium, lead(II) and sodium ions. Mercury interfered the most $\left(\log k_{\mathrm{Ag}, \mathrm{M}}=+2.0\right)$.

In this paper we report on the use of two novel calix [4] arene derivatives functionalized with two or four thioether $\left(-\mathrm{C}_{2} \mathrm{H}_{4} \mathrm{SCH}_{3}\right)$ groups as silver selective electrodes, and electrode characteristics as response time and pII-dependence are presented. In addition, some results of potentiometric titrations of halides, by using these electrodes in comparison with commercial silver electrodes, are reported.

\section{Experimental}

\subsection{Chemicals}

All salts employed were of analytical grade and were purchased from POCH (Gliwice, Poland). The standard stock solutions $(0.1 \mathrm{M})$ of metal nitrates were prepared in redistilled water; working solutions were obtained by dilution of the stock solution with redistilled water. The $\mathrm{pH}$ was adjusted by the addition of nitric acid or sodium hydroxide solutions.

\subsection{Ionophores and membrane materials}

The synthesis of ligands has been described previously [23]. High molecular weight poly (vinyl chloride) (PVC), potassium tetrakis (4-chlorophenyl) borate (KTpClPB), o-nitrophenyl octyl ether (oNPOE) and bis(butylpentyl)adipate (BBPA) were obtained from Fluka. As a solvent for the membrane components freshly distilled tetrahydrofuran (THF) p.a. (POCh Gliwicc) was uscd. 


\subsection{Membrane and electrode preparation}

The membranes contained 1 wt.\% ionophore, 75 mol\% KTpCIPB (relative to the ionophore), 65-66 wt.\% plasticizer, and 33 wt.\% poly(vinyl chloride) (PVC). The membrane components (200 $\mathrm{mg}$ in total) were dissolved in $2 \mathrm{ml}$ of freshly distilled tetrahydrofuran (THF). This solution was placed in glass ring of $24 \mathrm{~mm}$ i.d. resting on a glass plate. After solvent evaporation overnight, the resulting membrane was peeled off from the glass mould and discs of $7 \mathrm{~mm}$ i.d. were cut out. Membrane discs were mounted in electrode bodies (Type IS 561; Philips, Eindhoven, Netherlands) for electromotive force (EMF) measurements. As internal filling solution, a $0.005 \mathrm{M}$ solution of $\mathrm{AgNO}_{3}$ and $\mathrm{HNO}_{3}$ ( $\mathrm{pH}$ 2) was used. The electrodes were than conditioned overnight in a solution of 0.01 $\mathrm{M} \mathrm{KNO}_{3}$ and $0.001 \mathrm{M} \mathrm{AgNO}_{3}$. For each membrane composition two electrodes were prepared.

\subsection{EMF measurements}

All measurements were carried out at $20^{\circ} \mathrm{C}$ with cells of the following type: $\mathrm{Ag}$; $\mathrm{AgCl} ; \mathrm{KCl}(0.1 \mathrm{M}) / 0.1 \mathrm{M}$ $\mathrm{KNO}_{3} /$ sample solution//sensor membrane//internal filling solution; $\mathrm{AgCl} ; \mathrm{Ag}$.

The EMF values were measured using a custom made 16-channel electrode monitor. Details of this equipment are described elsewhere [24]. Potentiometric selectivity coefficients $\left(k_{\mathrm{Ag}, \mathrm{M}}\right)$ were determined by the fixed interference method $[25,26]$ by increasing the activity of primary ion in the solution in steps of $0.5 \log a_{\mathrm{Ag}}$, or for strong interfering ions by the separate solution method using $0.01 \mathrm{M}$ solutions of metal nitrates at a constant pH 4 (for mercury $\mathrm{pH} 2$ ). In these cases the experimentally obtained slope was used for the calculations. The activities of metal ions in aqueous solutions were calculated according to the DebyeHückel approximation [27]. The performance of the electrodes was examined by measuring of EMFs of the primary ion solutions with the concentration range $10^{-8}-10^{-1} \mathrm{M}$ in solutions stirred with a magnetic stirrer.

The response time ( $t_{95 \%}$ ) of the electrode was tested by measuring the time required to achieve a $95 \%$ steady potential for a $0.01 \mathrm{M}$ solution, when the $\mathrm{Ag}(\mathrm{I})$ ion concentration was rapidly increased by one decade from 0.0001 to $0.01 \mathrm{M}$.

\section{Results and discussion}

Ionophores (1 or 2) (Fig. 1) with a small amount of potassium tetrakis (4-chlorophenyl)borate (as lipophilic anionic sites) were incorporated in a plasticized PVC membrane. Two plasticizers, a polar o-NPOE and a non-polar BBPA wcrc investigated. Also membranes without the ionophores present were examined.

Fig. 2 shows the $\mathrm{Ag}^{+}$responses of electrode based on BBPA plasticized PVC containing ionophore 2 and $\mathrm{KTpCIPB}$ in the presence of some interfering cations.

All tested membranes showed a response towards silver ions but the calibration graphs obtained for membranes containing an ionophore were different for these 'bblank membranes"'. The results are demonstrated in Fig. 3a for the electrodes with the $o$-NPOE plasticized membranes and in Fig. 3b for the BBPA plasticized membranes. The "blank membranes" showed a linear response at the high concentrations of silver $\left(>10^{-3}\right.$ $\mathrm{M}$ ). In both cases the slope was less than Nernstian (ca. $41 \mathrm{mV} \mathrm{dec.}{ }^{-1}$ for $o-\mathrm{NPOE}$ and $43 \mathrm{mV} \mathrm{dec.}{ }^{-1}$ for BBPA). The detection limit for membranes with an ionophore incorporated was lower by 2 units but the response resembled an S-curve (except for the membrane with 2 and BBPA). This deviation from Nernstian response might be explained by the "sample anion effect" or by the formation of extremely stable complexes of ligands with cations [28]. According to the model calculations described by Cobben [29], this S-curve type of response can be caused by the outer boundary potential (membrane-sample solution). The association constant $\left(\beta_{1}\right)$ of complex formed between

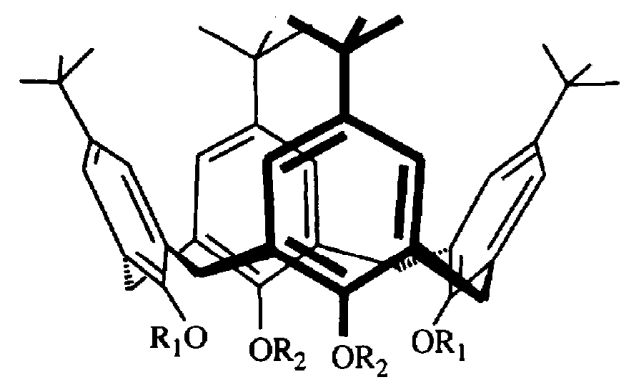

$1 \mathrm{R}_{1}=\mathrm{R}_{2}=\mathrm{CH}_{2} \mathrm{CH}_{2} \mathrm{SCH}_{3}$

$2 \mathrm{R}_{1}=\mathrm{H}, \mathrm{R}_{2}=\mathrm{CH}_{2} \mathrm{CH}_{2} \mathrm{SCH}_{3}$

Fig. 1. Struclures of ionophores. 


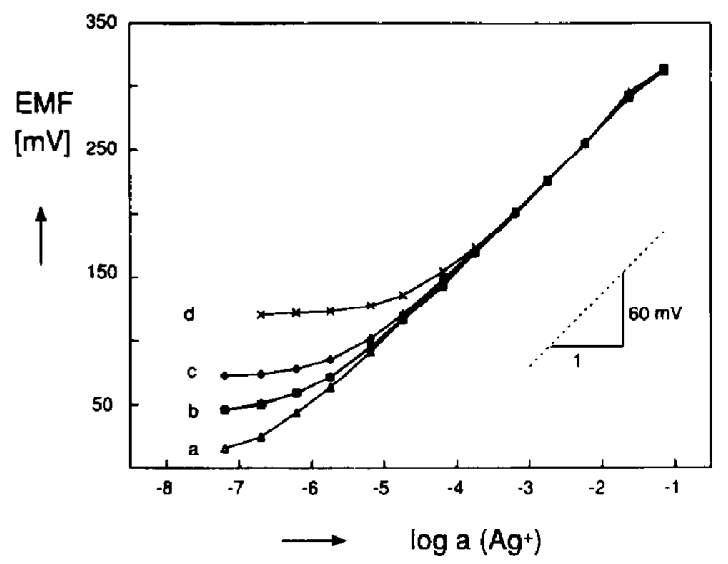

Fig. 2. Ag responses of electrodes based on ionophore 2 and BBPA as a plasticizer (with addition of $\mathrm{KTPClPB}$ ) in the presence of 0.1 $\mathrm{M}$ of interfering cations. (a) $\mathrm{K}^{+}$; (b) $\mathrm{Mg}^{2+}$ or $\mathrm{Cu}^{2+}$; (c) $\mathrm{Pb}^{2+}$; (d) $\mathrm{K}^{+}+10^{-4} \mathrm{M} \mathrm{Hg}^{2+}$.

the primary cation and the ionophore should be extremely high $\left(\beta_{1}=10^{13} \mathrm{~mol}^{-1}\right)$ to cause such an effect. As is shown in Fig. 3a the electrodes based on 1 with $a$-NPOE as a plasticizer exhibited Ag-response in a very narrow range of silver ion concentrations $\left(10^{-5.5}-10^{-3.5} \mathrm{M}\right.$ ) with the slope only $38 \mathrm{mV} /$ decade. In this case the deviation from Nernstian response was the largest. For this electrode the influence of the concentration of the anionic site $(0-90 \mathrm{~mol} \%$ relatively to the ionophore) was studied. We found that the variation in the ratio KTpClPB to the ionophore did not substantially influence the response. With ionophore 2 and oNPOE the slope of the linear response was close to the theoretical value $(53.8 \mathrm{mV} /$ decade $)$ and in a wider range of $\mathrm{Ag}^{+}$concentrations.

It is known that in sensors for monovalent cations the use of relatively nonpolar membrane materials can improve the cation response $[28,29]$. This has been confirmed experimentally for ionophores 1 and 2 . With BBPA as the plasticizer the linear response range for both ionophores ( $\mathbf{1}$ and $\mathbf{2}$ ) becomes larger although for ionophore $\mathbf{1}$ a deviation from linearity at higher silver concentrations was observed.

Three compositions of a PVC membrane with KTpCIPB: (1-BBPA), (2-BBPA) and (2-o-NPOE) have been studied in greater detail. The selectivity, response to the silver(I) ions concentration (slope and detection limit), $\mathrm{pH}$ dependence, and response time were measured. The results are given in Table 1 . The logarithmic values of the selectivity coefficients (expressed as $\log k_{\mathrm{Ag}, \mathrm{M}}$ ) are presented in Fig. 4. The preference for silver over other monovalent cations was more significant for membranes plasticized with $o$ NPOE than BBPA. It seems that without ionophore the selectivity is related to the hydration energy [30]. The incorporation of the ligand 1 or $\mathbf{2}$ into the membrane phase substantially affected the selectivity of the membranes as compared with the "blank membranes". For both ligands, and both plasticizers, the selectivity coefficients $\left(\log k_{\mathrm{Ag}, \mathrm{M}}\right)$ were lower than -4.6 for all cations tested, except mercury. The interference of mercury was more severe but still a selective response was found for $o$-NPOE plasticized membranes containing ligand 1 or 2 . The selectivity of the substituted bis [2-(meth-
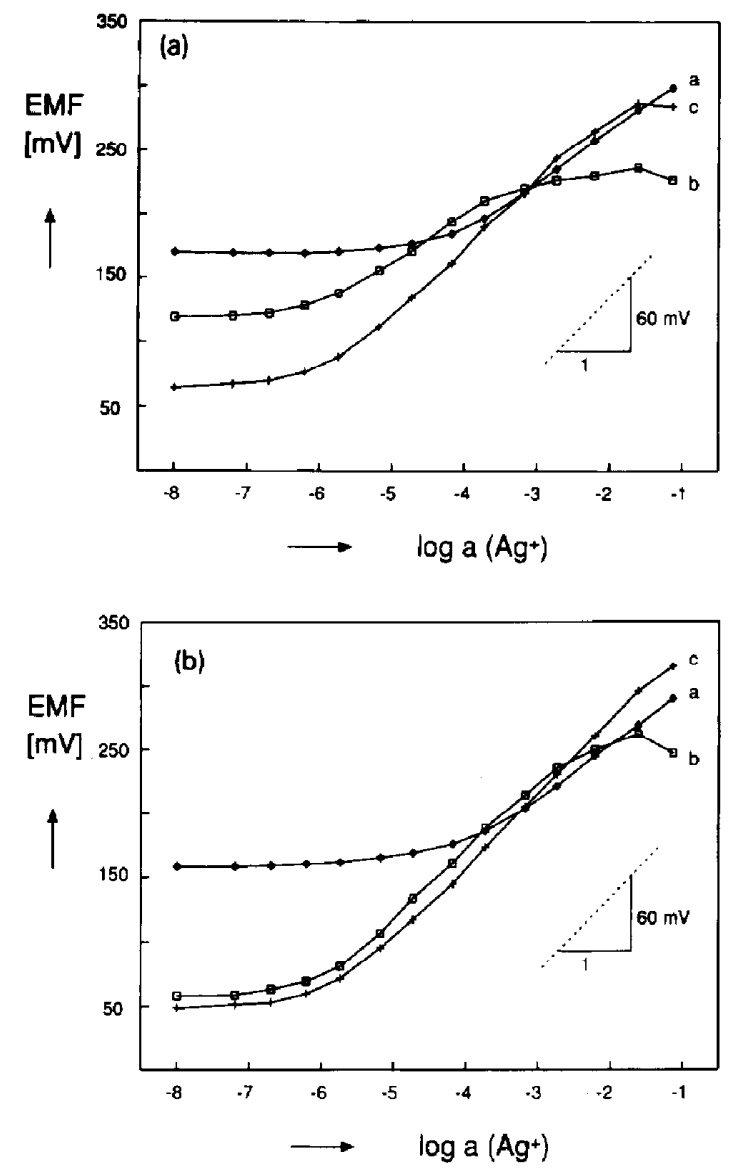

Fig. 3. (a) Ag responses of electrodes based on ionophores 1 or 2 and $o$-NPOE as a plasticizer (with KTpClPB) in the presence of 0.1 $\mathrm{M} \mathrm{Mg}\left(\mathrm{NO}_{3}\right)_{2}$. (a) Without ionophore; (b) ionophore 1; (c) ionophore 2. (b) Ag responses of electrodes based on ionophores 1 or 2 and BBPA as a plasticizer (with KTpClPB) in the presence of 0.1 $\mathrm{M} \mathrm{Mg}\left(\mathrm{NO}_{3}\right)_{2}$. (a) Without ionophore; (b) ionophore 1; (c) ionophore 2. 
Table 1

Properties of $\mathrm{Ag}^{+}$selective membrane electrodes based on tetrakisthioether calix [4] arene 1 and bisthioether calix [4] arene 2 (PVC, o-NPOE or BBPA, 75 mol\% KTpCIPB)

\begin{tabular}{|c|c|c|c|c|}
\hline & \multicolumn{2}{|l|}{1} & \multicolumn{2}{|l|}{2} \\
\hline & $a-\mathrm{NPOE}$ & BBPA & $o$-NPOE & BBPA \\
\hline Slope $(\mathrm{mV} /$ dec. $)$ & 38.3 & 54.7 & 53.7 & 56.7 \\
\hline Response time, $t_{95 \%}(\mathrm{~s})$ & & $<15$ & $<10$ & $<10$ \\
\hline Linear range $(\log a)$ & $<-3.5$ & $<-3.0$ & $<-2.5$ & $<-1.0$ \\
\hline Detection limit & -5.5 & -5.5 & -6.0 & $-5,4$ \\
\hline pH range & & $>3$ & $>2.5$ & $>2.5$ \\
\hline Drift $^{a}$ ( $\mathrm{mV} /$ day) & -2.6 & -0.02 & 1.0 & -0.36 \\
\hline
\end{tabular}

a Drift of measured potential for $0.01 \mathrm{M} \mathrm{AgNO}_{3}$ solutions.

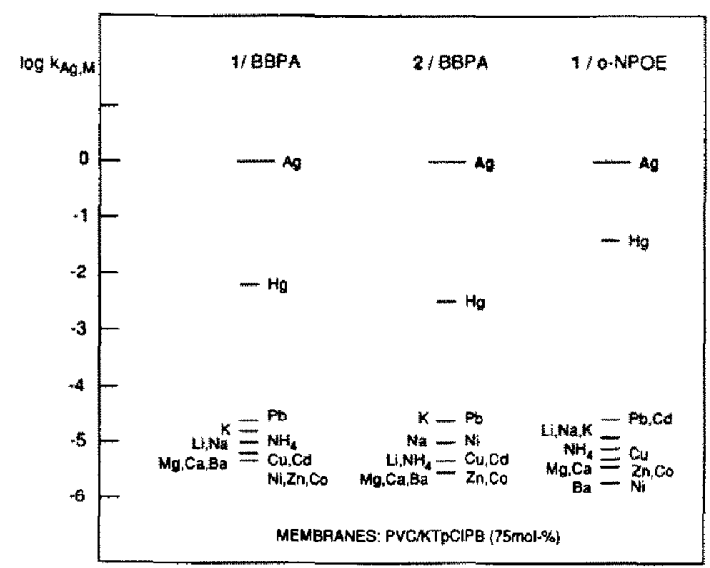

Fig. 4. Selectivity coefficients, $\log k_{\mathrm{Ag}, M}$, for PVC membranes containing ionophore 1 or 2 , anionic sites KTPCIPB and 0 -NPOE or BBPA as plasticizer [0.1 $\mathrm{M}$ solutions of nitrates, $\mathrm{pH} 4$, internal electrolyte: $0.05 \mathrm{M} \mathrm{AgNO}_{3}+\mathrm{HNO}_{3}, \mathrm{pH} 2$ ].

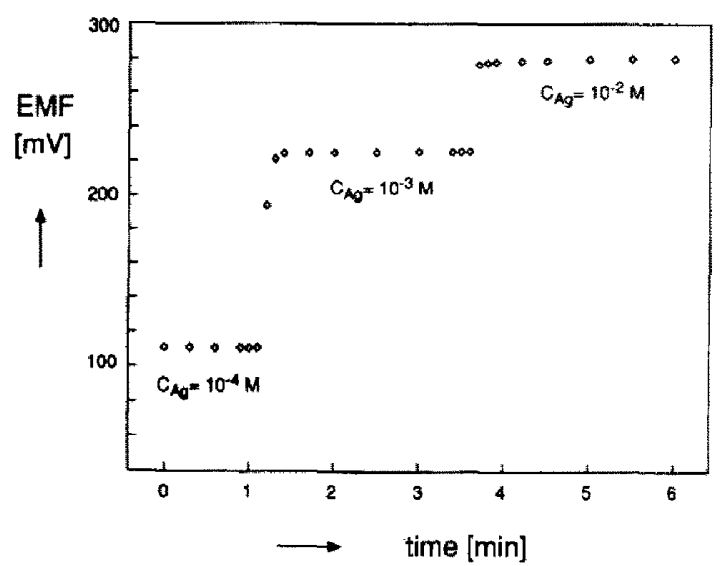

Fig. 5. Response time of electrodes based on ionophore 2 and BBPA as a plasticizer (with addition of KTpClPB) in the presence of 0.1 $\mathrm{M} \mathrm{KNO}_{3}$. ylthio)ethoxy] calix [4] arene (2) was slightly better $(-2.5)$ than of the tetra[2-(methylthio) ethoxy]calix [4] arene (1) $(-2.2)$. This leads to the conclusion that the number of sulfur donor atoms in the receptor molecule does not influence significantly the selective complexation of silver(I) ions. $o$-NPOE gave an increased selectivity coefficient of about 1 unit.

The response time $\left(t_{95 \%}\right)$ of the electrodes was tested by measuring the time required to achieve a $95 \%$ steady potential for a $10^{-2} \mathrm{M}$ solution, when the silver ion concentration was rapidly increased one decade from $10^{-4}$ to $10^{-3} \mathrm{M}$ and from $10^{-3}$ to $10^{-2} \mathrm{M}$. The response time was slightly longer for $1(<15 \mathrm{~s})$ than for 2 based membranes ( $<10 \mathrm{~s}$ ). The results obtained for the electrode based on ligand 2, BBPA as a plasticizer, and KTpCIPB are presented in Fig. 5.

The $\mathrm{pH}$ dependence of the electrode response was examined using $10^{-4}, 10^{-3}$ and $10^{-2} \mathrm{M}$ silver solutions. The electrodes are not $\mathrm{pH}$ sensitive in the range of $\mathrm{pH} 2.5-6$. The upper $\mathrm{pH}$ limit is due to silver hydroxide formation. Fig. 6 shows the effect of $\mathrm{pH}$ on the response of 2-BBPA electrode. Similar profiles were observed for other electrodes. These electrodes have been tested for 60 days. Properties of the electrodes are summarized in Table 1.

All electrodes were used in potentiometric titrations of halide ions $\left(\mathrm{I}^{-}, \mathrm{Br}^{-}, \mathrm{Cl}^{-}\right)$with silver nitrate and their performance was compared with commercial silver selective electrodes (metallic and solid state). The results presented in Fig. 7a and $b$ show that:

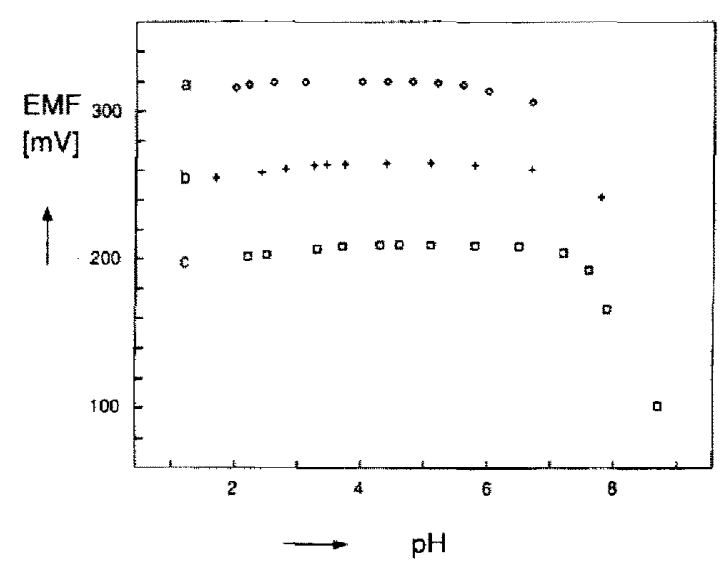

Fig. 6. pH response of $\mathrm{Ag}$ selective electrodes based on ionophore 2 and BBPA as a plasticizer (with addition of $\mathrm{KTpCIPB}$ ) in the presence of $0.1 \mathrm{M} \mathrm{KNO}_{3} . \mathrm{C}_{\mathrm{Ag}(1)}$ : (a) $10^{-2} \mathrm{M}$; (b) $10^{-3} \mathrm{M}$; (c) $10^{-4}$ M. 

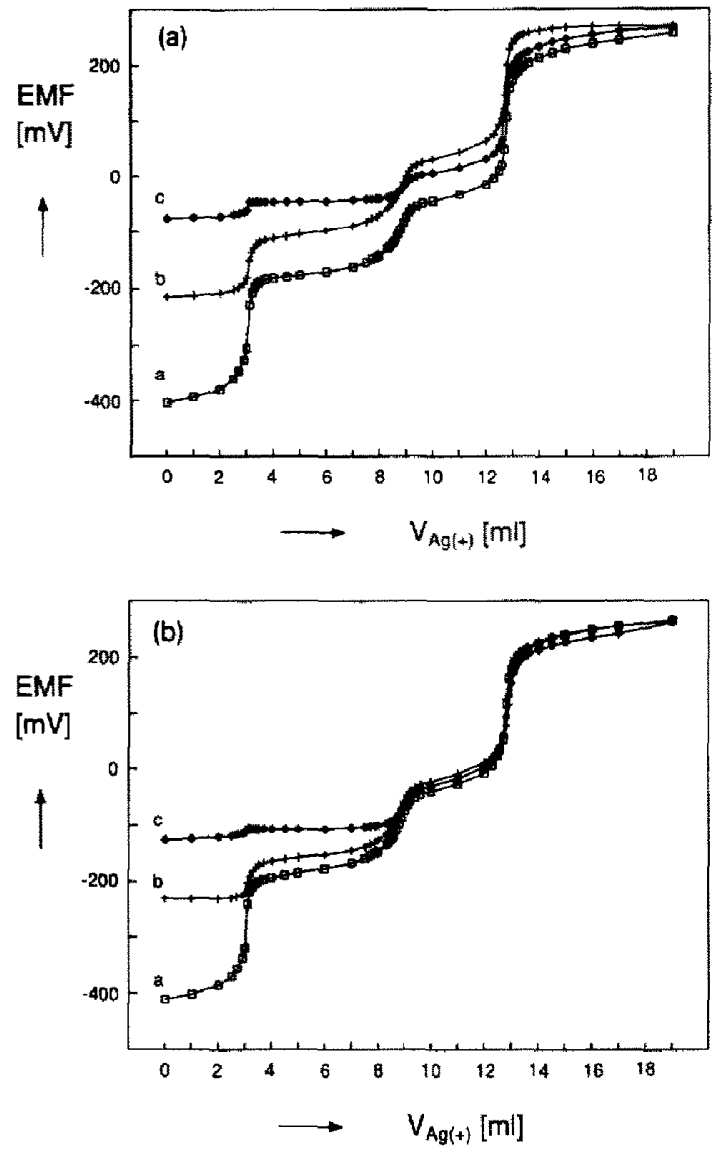

Fig. 7. (a) Potentiometric titration curves of a mixture of $4 \mathrm{mI} \mathrm{KI}, 6$ $\mathrm{ml} \mathrm{KBr}$ and $4 \mathrm{ml} \mathrm{KCl}$ (all $0.1 \mathrm{M}$ ) with $0.1 \mathrm{M} \mathrm{AgNO}_{3}$ with: (a) metallic silver electrode; (b) Ag ISE based on ionophore 1 and $o$ NPOE; (c) Ag ISE based on ionophore 1 and BBPA. (b) Potentiometric titration curves of a mixture of $4 \mathrm{ml} \mathrm{KI}, 6 \mathrm{ml} \mathrm{KBr}$ and $4 \mathrm{ml}$ $\mathrm{KCl}$ (all $0.1 \mathrm{M}$ ) with $0.1 \mathrm{M} \mathrm{AgNO}_{3}$ with: (a) solid-state silver electrode; (b) Ag ISE based on ionophore 2 and $o$-NPOE; (c) Ag ISE based on ionophore 2 and BBPA.

(i) Using electrodes with $o$-NPOE plasticized membranes containing ligand 1 as well as 2 three end-points of this titration could be defined. However, the potential changes at the end-point, which corresponds with the determination of $\mathrm{I}^{-}$ions, are significantly lower for these electrodes as compared with both metallic and solid-state ion-selective electrodes while for $\mathrm{Br}^{-}$and $\mathrm{Cl}^{-}$ions potential changes are similar.

(ii) For both electrodes with BBPA the end-point for $\mathrm{I}^{-}$ions is imperceptible. Even for $\mathrm{Br}^{-}$ions the end point is lower as compared with $1-0$-NPOE and $2-o$ NPOE as well as two commercial silver electrodes. (iii) It seems that the true detection limit of the electrodes tested is lower than that obtained for solutions which were not metal buffer solutions for silver.

\section{Conclusions}

The present results suggest that calix[4] arenes derivatives containing thioether groups show high selectivity and, when the BBPA is used as a plasticizer, sensitivity towards silver ions. The best results were obtained for membranes containing dithioether functionalized calix [4] arene (ionophore 2), KTpCIPB and BBPA as a plasticizer. The determination of silver is possible over a wide range of concentrations in the presence of alkali, alkaline, and heavy metals ions. For mercury(II) ions the $\log k_{\mathrm{Ag}, \mathrm{M}}$ values are -2.5 and comparable to the best ISE known so far.

\section{Acknowledgements}

This work was supported by the Polish State Committee for Scientific Research; Project No. 2077591 01 sponsored in 1991-1994.

\section{References}

[1] T.S. Light and J.L. Swartz, Anal. Lett., 1 (1968) 825.

[2] M. Mascini and A. Liberti, Anal. Chim. Acta, 51 (1970) 231.

[3] E. Schmidt and E. Pungor, Anal. Lett., 4 (1971) 641.

[4] J. Vesely, O.J. Jensen and B. Nicolasen, Anal. Chim. Acta, 62 (1972) 1 .

[5] C. Litenau, I.C. Popescu and V. Ciovirnache, Talanta, 19 (1972) 985 .

[6] Y. Umezawa (Ed.), Handbook of lon-Selective Electrodes: Selectivity Coefficients, CRC Press, Boca Raton, FL, 1990.

[7] W.E. Morf, G. Kahr and W. Simon, Anal. Chem., 46 (1974) 1538 .

[8] A.K. Jain, R.P. Singht and S. Agrawal, Anal. Chem., 51 (1979) 1093.

[9] Yu.G. Vlasov, Fresenius' Z. Anal. Chem., 335 (1989) 92.

[10] J. Pei, Q. Yin and J. Zhong, Talanta, 38 (1991) 1185.

[11] B.P. Bubnis, J.L. Steger, Y.P. Wa, L.A. Meyers and G.E. Pacey, Anal. Chim. Acta, 139 (1982) 307.

[12] K. Kimura, H. Yano, S. Kitazawa and T. Shono, J. Chem. Soc,, Perkin Trans. II, (1986) 1945.

[13] K. Kimura. H. Oishi, T. Miura and T. Shono, Anal. Chem., 59 (1987) 2331.

[14] C.J. Pedersen, J. Org. Chern., 36 (1971) 254. 
[15] M.T. Lai and J.S. Shih, Analyst, 111 (1986) 891.

[16] M. Oue, K. Kimura, K. Akama, M. Tanaka and T. Shono, Chem. Lett., (1988) 409.

[17] M. Oue, K. Akama, K. Kimura, M. Tanaka and T. Shono, J. Chem. Soc., Perkin Trans. I, (1989) 1675.

[18] M. Oue, K. Akama, K. Kimura, M. Tanaka and T. Shono, J. Anal. Sci., 5 (1989) 165.

[19] J. Casabo, C. Perez-Jimenez, L. Escriche, S. Alegret, E. Martinez-Fabregas and F. Teixidor, Chem. Lett., (1990) 1107.

[20] J. Casabo, L. Escriche, S. Alegret, C. Jaime, L. Mestres, F. Teixidor, C. Perez-Jimenez, J. Rius, E., Molins and C. Miravitlles, Inorg. Chem., 30 (1991) 1893.

[21] J. Casabo, L. Mestres, L. Escriche, F. Teixidor and C. PcrezJimenez, J. Chem. Soc., Dalton Trans., (1991) 1969.

[22] K.M. O'Connor, G. Svehla, S.J. Harris and M.A. McKervey, Talanta, 39 (1992) 1549.
[23] P.L.H.M. Cobben, R.J.M. Egberink, J.G. Bomer, P. Bergveld, W. Verboom and D.N. Reinhoudt, J. Am. Chem. Soc., 114 (1992) 10573.

[24] Z. Brzózka, Pomiary, Automatyka, Kontrola, 5 (1988) 422.

[25] G.G. Guilbault, R.A. Durst, M.S. Frant, H. Freiser, E.H. Hansen, T.S. Light, E. Pungor and J.D.R. Thomas, Pure Appl. Chem., 48 (1976) 127.

[26] A. Lewenstam and A. Hulanicki, Selective Electrode Rev., 12 (1990) 161.

[27] P.C. Meier, Anal. Chim. Acta, 136 (1982) 363.

[28] D. Ammann, W.E. Morf. P.C. Meier, E. Pretsch and W. Simon, Ion-selective Electrode Rev, 5 (1983) 16.

[29] P.L.H.M. Cobben, Ph.D. Thesis, University of Twentc, Enschede, 1992.

[30] Y. Marcus, in Ion solvation, Wiley, New York, 1985, pp. 107109. 